\title{
BRIAN WHITE
}

\section{4}

\section{Foreign policy analysis and European foreign policy}

This chapter addresses two key objectives of this book identified in the introductory chapter. It makes a case for a new theoretical approach to the study of the European Union as a global actor based explicitly upon an adapted foreign policy analysis. It also seeks to broaden the focus of the analysis from the Common Foreign and Security Policy to the much more broadly based concept of European foreign policy. The chapter begins by reflecting upon the limitations of existing theoretical approaches, the pervasive institutionalist approach in particular, which provides a justification for developing a rather different approach here. Before an FPA framework can be set up, however, two sets of clarifications are needed. First, we need to demonstrate that FPA can be adapted from its traditional state-centric focus which appears to be inappropriate in an EU context. Second, we need to establish the alternative focus of the analysis here. The EU's global role will be analysed in foreign policy terms by reference to the controversial idea of European foreign policy which needs some preliminary discussion. After developing an FPA framework for analysing European foreign policy, the final section of this chapter reports briefly on this author's attempt to apply the framework in a book-length study elsewhere.

\section{Contending approaches to European foreign policy}

There are two different approaches in the literature that arguably dominate existing analyses of Europe's global role. The first, the 'European Union-asactor' approach, concentrates on the impact of Europe on world politics. Working backwards, as it were, from impact, scholars have tried to identify what sort of an 'actor' Europe is that has enabled it to be such an influential global player. Implicitly or explicitly, the working model has been the state, but increasingly scholars have moved beyond a state model to identify a distinctive non-state but 
nevertheless collective entity, with the European Community and latterly the European Union providing the 'actor' focus of the analysis. This approach has made a major contribution to our understanding of Europe's global role in both empirical and conceptual terms (Whitman 1997; Bretherton and Vogler 1999).

Important though this body of work has undoubtedly been in developing our understanding of Europe's global role, it can be argued that the EU-as-actor approach is limited in two particular respects. First, the focus is on outcomes rather than process. As Bretherton and Vogler admit in their study, they are primarily concerned to assess 'the overall impact of the EC/EU' on world politics (1999: 2-3). They are much less concerned with analysing the processes through which EU foreign policy is formulated. Indeed, they explicitly reject a policy analysis approach to understanding EU foreign policy. A different view is taken and a different policy-oriented approach is offered here. The foreign policy analyst is less concerned with explaining and evaluating policy outcomes and more concerned to understand and to explain the policy process itself - how policy emerges, from whom or what, and why. To the extent that 'actorness' or, in Allen and Smith's formulation, 'presence' characterises the EU in world politics, the assumption here is that this is related to and emerges from elements of a foreign policy system in action, such as the context in which policy is made, the nature of the policy process, the instruments used, the issue in question, and so on (Allen and Smith 1990).

A second problem area with this approach is the assumption that the EU can be appropriately analysed and evaluated as a single actor. The position taken here is that to conceive of the EU as an actor, $a$ 'presence' or an 'international identity' - in short to adopt a holistic approach to analysis which focuses on 'singleness' or 'unitariness' - is to misrepresent what Jørgensen calls the 'multiple realities' that constitute the European Union (Jørgensen 1998: 12). Hence the assumption here is that the EU is more appropriately analysed as a non-unitary or disaggregated entity in world politics.

The other popular approach in the literature is very different from the first in terms of the perspective from which the EU is analysed. This approach can broadly be located within neo-liberal institutionalism which, rather than focusing on actor-generated behaviour, provides an explanation of actor behaviour as a function of the international institutions or other structures within which actors are located (see for example Ifestos 1987 and Allen et al. 1982; Nuttall 1992; Regelsberger et al., 1997). The essential focus of neo-liberal, and indeed neorealist, approaches is on structures rather than actors; hence they have also been characterised as 'structuralist' approaches (Hill 1996a: 6). Though not initially developed in a European context, the relevance of institutionalist thinking to the increasingly institutionalised process of European cooperation and integration is evident. Indeed, institutionalist ideas have stimulated the integration process in Europe, and the EU is an important test case of institutionalist expectations about regional and international cooperation. EU foreign policy has not been a major preoccupation for institutionalists but they too have made a significant 
contribution to our understanding of Europe's global role. First, as their label suggests, they have been fascinated by the growth of EC/EU institutions and the extent to which decision-making has become institutionalised. They have analysed the ways in which institutions like the European Commission have constructed their own agenda and developed their own capabilities, enabling them to act increasingly independently of states.

Second, the new institutionalists have become increasingly interested in analysing member state behaviour, identifying ways in which states have adapted their behaviour as a result of operating within an EU institutional context. They have noted that the broadening agenda of European integration has tended to strengthen institutional and weaken governmental control. Third, institutionalists have been well placed to observe that the EU is not simply an intergovernmental system of states but is characterised by a wider range of policy processes, including transnational, transgovernmental and supranational processes. Finally, the regional/global perspective of institutionalists has highlighted the relationship between Europe's global role and global processes like interdependence and globalisation. From this perspective, institutionalised European integration can be seen as a regional response to important global trends.

But structuralist approaches also have their limitations, stemming largely from the level at which they analyse the behaviour of states and other actors. What might be called the 'actor problem' is the first in a set of interrelated problems. The assumption that systemic imperatives (whether the system is conceived of in global or regional terms) determine the behaviour of the actors within the system leaves little room to explain those occasions when the state or some other actor does not behave in accordance with the dictates of the system. Clearly, for those occasions at least, some other, more actor-centred perspective is required which investigates the particularity of the actors. As Christopher Hill notes, this is an important illustration of the collective action problem that has concerned political theorists for many years. He suggests that states 'find it genuinely difficult both to reach agreement on group strategies and then to hold to these strategies once agreements are reached'. Significantly, he adds, 'solidarity is the exception rather than the rule - even in Western Europe' (Hill 1996a: 7) An analytical focus on states themselves (or other actors) is required to make sense of what may be called a predisposition to defect or 'free ride'. This is a major problem for institutionalists who are concerned primarily to explain international cooperation from a systemic perspective.

If structuralists are weak on agency, it follows that their conception of the foreign policy process within states and their understanding of the role of domestic factors in that process will also be underdeveloped or understated at best. Certainly a focus on structural imperatives leads to a simplified view of policy processes. If the behaviour of states and other actors is essentially determined by international structures, the assumed reaction of those actors will be limited to recognising what they are required to do by the system and adapting their behaviour more or less effectively. While acknowledging important work 
by structural theorists who seek to introduce domestic factors into their analyses, what has emerged is a reintroduction of the 'rational actor model' of state behaviour described in the next section (Moravcsik 1991; Buzan et al. 1993). The resulting picture of an integrated political elite in one state bargaining with similar elites in other states by manipulating the interests or 'preferences' of the state according to rationalist principles may capture important elements of the foreign policy process but, as Hill argues, this focus offers 'a somewhat impoverished view of politics in general and the domestic environment in particular' (Hill 1996a: 11).

There is a problem relating structuralist imperatives to an understanding of Europe's global role and there is a need to complement the 'macro' approach of institutionalism-structuralism with some form or forms of 'micro', actor-centred analysis but which, unlike the EU-as-actor approach, do not make inappropriate assumptions about single 'actorness'. The central question is whether FPA can be adapted to fill this role in a European context.

\section{The adaptability of foreign policy analysis}

One of the main arguments of critics of FPA is that despite the transformed nature of contemporary world politics, FPA is outdated because it is still locked into 'state-centric realism' with, as Michael Smith puts it, 'the state and governmental power' still providing the 'central conceptual building block of the field' (Smith 1994: 22). Marjorie Lister's study of the European Union illustrates a view that FPA is unable to throw any light on the EU's external relations. Not only does the EU not have a foreign policy, in Lister's view, but 'the tools of traditional foreign policy analysis add relatively little to our understanding of the $\mathrm{EU}$. The EU is best understood as a unique type of institution rather than an embryonic state' (Lister 1997: 6).

A response to these criticisms requires some understanding of the development of FPA as a field of study. In the 1970s, Jo Nye labelled the traditional foreign policy analysis approach, 'state-centric realism' (Nye 1975). Three assumptions underpin this approach. First, state-centricity captures the assumption that states are the most important actors in the international system; consequently, it is their foreign policy behaviour rather than any other actors that interests foreign policy analysts. Second, the idea of the state-as-actor denotes the assumption that states act in the international arena as unitary, rational actors (Allison and Zelikow 1999). State behaviour, in other words, is assumed to be analogous to that of a rational individual. Third, reference to realism in this context denotes the idea that assumptions about the state are in turn linked to realist assumptions about the nature of the international system. In particular, given assumptions about the anarchic nature of that system, states are assumed to be preoccupied in their foreign policy behaviour with military-security and with issues and instruments associated with security. From this perspective, security politics conceived of 
in military terms defines the essence of state behaviour and, indeed, of world politics.

The development of FPA as a field of study can be seen as a response to challenges to these traditional assumptions (Clarke and White 1989; Halliday 1994). The first major challenge came in the 1950s with the introduction of decision-making analysis which led to foreign policy behaviour being analysed less as a response to a hostile, anarchic international environment and more as a process essentially internal to the state. Building upon the work of Graham Allison and others, analysts developed a solid body of knowledge about the way foreign policy processes work and the relationships between process and output. A behaviouralist approach with a focus on trying to explain the behaviour of decision-makers rather than the abstract 'state' appeared to constitute a major attack on realist assumptions (White 1978).

With hindsight, however, we may argue that the decision-making approach offered a limited critique only of traditional assumptions. While both the idea of the unitary, rational 'state' and realist assumptions were undermined, the state-centric focus of FPA was left relatively unscathed. Indeed, critics of FPA argued that the decision-making approach was leading foreign policy analysts into an excessive preoccupation with the domestic context of foreign policymaking and, consequently, predisposing them to take insufficient account of important changes in the international environment (Light 1994). While foreign policy analysts were indeed focusing on domestic policy processes, major transformations in the international environment were being analysed by other IR scholars.

The cumulative impact of these changes was to undermine all the traditional assumptions of FPA including, critically, the assumption that states and governments remain the only important actors in world politics. In broad terms, these changes, conveniently organised here in terms of actors, processes and issues, challenged traditional FPA assumptions as follows.

State-centricity has been challenged by an evident increase in the forms and variety of states in the international system, the changing roles and functions of developed states in particular, and the emergence of a range of non-state actors operating at different levels of activity. What has been characterised as a more complex 'mixed actor' international system (Young 1972) raises fundamental questions about the nature of statehood and poses a major challenge to foreign policy analysts. State-centricity is further challenged by related processes like interdependence and transnationalism which directly challenge the autonomy of states and their ability to control outcomes (Keohane and Nye 1977).

Significantly, both state-centric and state-as-actor assumptions have been undermined by what Keohane and Nye refer to as transgovernmentalism. This denotes the predisposition of subunits of governments to form international coalitions across national boundaries and to operate on the basis of shared interests which might undermine the operation of 'national interests' in policymaking processes (Keohane and Nye 1974). 
Security politics assumptions derived from a traditional realist account of international relations have been directly challenged by the new agenda of world politics, an agenda which is itself a product of both the changing role and function of the state - in particular the growing welfare functions of the modern state - and a changing international environment. This agenda consists of a far wider range of issues than military-security; indeed, security itself has been redefined in much broader terms that go beyond the military-defence arena (Buzan 1983). One of the defining features of newer processes like interdependence and integration is that they are less conflict-oriented and more geared to achieve cooperation between states and other actors.

If we consider the overall challenge to FPA that these changes represent, we might reach one of two conclusions. One conclusion is to accept the view of critics that these changes fundamentally undermine FPA to such an extent that it is no longer a helpful way of understanding world politics. Many IR scholars have indeed concluded either implicitly or explicitly that states and the governments that represent them no longer constitute a useful level of analysis from which to make sense of world politics. The key structuralist assumption, as we noted above, is that the structure of the international system effectively determines the behaviour of its constituent units, therefore the international system itself is the appropriate level from which to analyse the workings of the system. Hence, various types of structuralist accounts of IR have predominated in recent years to the partial exclusion at least of explanations like FPA.

The other, less radical conclusion advanced here rejects the idea that FPA is anachronistic but recognises that FPA must be further adapted to take account of a transformed international system. The importance of the European case here is that the global changes outlined above are more clearly illustrated in Europe than in any other region in world politics. It might be argued, therefore, that if foreign policy analysts can use their analytical techniques to make sense of European foreign policy, this will not only throw light on an important new area of foreign policy activity but will also make a major contribution to the development of FPA as a field of study.

Clearly, much hinges on the extent to which FPA is still wedded to 'statecentric realism'. Looking first at state-centricity, there appears to be no obvious reason why the perspective of, and the analytical techniques associated with, FPA cannot be transferred from the state to other significant international actors or, indeed, mixed actor systems. After all, FPA emerged as a major field in IR during the early post-war period when there were no serious challengers to the state and it was logical to base a 'micro' analysis of international relations upon the state, evidently the most significant actor within the international system. But, arguably, it was always the actor perspective rather than a specific actor or actors that was important to the foreign policy analyst (Hill 1974).

If replacing 'state' with 'actor' appears to do no fundamental damage to an FPA perspective, what of the associated focus on government and governmental power? Clearly, the emergence of what Stephen Krasner has called 'authority 
structures that are not coterminous with geographic borders', whether territorially or regionally based (like the EU) or issue based, has to a greater or lesser extent posed problems for all political scientists (Krasner 1995: 116). The solution elsewhere has been to substitute the term 'government' with the term 'governance' to facilitate a study of government-like activities. As with replacing state by actor, it does not obviously damage the essence of an FPA approach to replace government with governance. Indeed, if governance is taken to subsume government, it can provide a framework for analysing policy-making and policy outcomes that emerge from a political system like the EU which is constituted by interactions between traditional 'authority structures' (i.e. states and governments) and newer forms of non-state authority (Rosenau 1992: 3-6). The focus on policy at the international level is arguably what is important to the foreign policy analyst rather than whether the actor is a conventional government or not.

Finally, what of the relationship between FPA and realism? The brief overview of the development of the field presented here suggests that there is no necessary connection. Certainly, foreign policy analysts have not been content to accept uncritically the idea of the state as a unitary, rational actor struggling to survive in an anarchic international environment or the associated simplicities of a traditional power analysis of state behaviour. Stimulated by the introduction of a decision-making approach, analysts have persistently looked within the 'billiard ball' state to identify key decision-makers and to unravel the domestic processes of foreign policy decision-making. While the now conventional attempts, following the pioneering work of Graham Allison, to disaggregate the state-as-actor and to 'domesticate' foreign policy have attracted criticism for understating the extent to which state behaviour is constrained by the international system, it would be difficult to maintain that FPA at the beginning of the twenty-first century is hopelessly tied either to statecentricity or to a realist agenda.

\section{Reflections on European foreign policy}

Having made a case for the adaptability of FPA as an approach but before taking a look at how an FPA framework might be developed in a European context, it is important at this point to clarify exactly what we mean by 'European foreign policy', the putative focus of the analysis here. Why 'European' rather than 'EU' foreign policy? Problems with the holistic EU-as-actor approach have already been discussed. Another reason for staying with 'Europe' rather than 'European Union' as the qualifying adjective is to capture more effectively developments in Europe since the end of the Cold War. Prior to the 1990s, the process of integration in Europe was limited by ideological East-West divisions to Western Europe. The end of the Cold War has now resulted in the inclusion of states formerly Eastern Europe in the integration process. Whether or not all these states eventually join the European Union, a Europe-wide foreign policy is now 
at least a theoretical possibility that should not be ruled out by unnecessarily restrictive language.

But we do need to recognise that the notion of a European foreign policy is a controversial idea subject both to sharp intellectual debate and to the same passions and emotions that the whole process of European integration evokes (Hill 1992: 109-10). Any discussion of European foreign policy, in short, is part of the wider debate about European integration and, as such, is a very live political issue. Intellectuals, politicians, journalists and the 'attentive public' in Europe and elsewhere take at least three different views on the possibility and the desirability of a European foreign policy:

One view is that European foreign policy already exists though that term may not be used. From this perspective, it is an integral part of the process of European integration which increasingly - particularly since the Single European Act, the Treaty on European Union and the subsequent treaties signed at Amsterdam and Nice - has a strong foreign, security and defence dimension to it.

A second view is that a European foreign policy does not yet exist but it should. Problems illustrated by the inadequate collective European performance in the succession of crises in the Balkans are taken as a clear indication that a common or even a 'single' European foreign policy is needed to deal effectively with such issues.

A third view is that European foreign policy does not exist, it never will and, moreover, it never should! Proponents of this view are wedded to the idea that the ability to control foreign and defence policy is a fundamental, defining characteristic of the nation-state. Accepting both the concept and the reality of a European foreign policy would mean nothing less than member states giving up both independence and sovereignty and must lead inexorably to the early demise of the nation-state.

This last view, it should be noted, is linked theoretically to a 'state-centric realist' perspective which maintains that foreign policy is essentially the preserve of states and governments. If EU member states wish to retain national foreign policies they cannot also be a party to something called European foreign policy. The latter is a contradiction in terms at best and a myth at worst. David Allen, for example, argues that 'the determination to preserve national foreign policies is ultimately at odds with the ambition to create a European foreign policy' (Allen 1998: 42; see also Allen 1996). Quite simply, the EU is not a state - it may well never be - and therefore it does not qualify as a foreign policy actor. Indeed, from this perspective, the very concept of a 'European foreign policy' is an intrinsic part of an ideological, federalist vision of Europe and the logical corollary is that a 'European foreign policy worthy of the name' must await a federal European state (Hill 1993a: 316).

What might constitute European foreign policy from a broadly state-centric realist perspective is the sum of member states' foreign policies studied as a limited set of cases in an exercise (implicit or explicit) in comparative foreign policy analysis (Hill 1983; Stavridis and Hill 1996). At first sight, Roy Ginsberg's 
influential work on foreign policy actions in the EC looks like a useful model to build upon, with foreign policy defined as 'the process of integrating policies and actions of the member states' (Ginsberg 1989: 1). That definition and the ensuing analysis make it clear, however, that Ginsberg's ostensibly state-centric approach is essentially locked into a structuralist perspective. He looks first to integration theory and global interdependence to explain foreign policy, invoking what he calls 'self-styled logic' (internal decision-making and political dynamic) only when actions are not taken in response to outside pressures (Ginsberg 1999).

Ginsberg is unusual, nevertheless, in including all of the external relations of the Community within his analysis of 'foreign policy actions'. Much more typically from an institutionalist perspective, as Hazel Smith points out, European foreign policy has been rather narrowly defined both in scope and level by the way 'foreign policy' is defined at the level of the European institutions themselves (1998: 154-7). Thus, European foreign policy viewed through the lens of the standard institutionalist literature is synonymous (since 1993) with EU foreign policy. It refers to the process of foreign policy coordination known as European political cooperation which began in the 1970s and was upgraded by the Maastricht Treaty into a Common Foreign and Security Policy in 1993 and subsequently amended by the Amsterdam and Nice Treaties.

From an institutionalist perspective, moreover, EPC/CFSP is 'real' European foreign policy (despite the resistance to actually using the words 'foreign, and 'policy' until 1993) which can be contrasted with the external powers or 'competences' originally established by the Treaty of Rome which are generally labelled 'External Relations'. If this narrows the scope of European foreign policy to the processes and the outcomes of EPC/CFSP with significant political implications, the contribution of individual member states' foreign policies to European foreign policy is either downgraded by the institutionalists, with their focus on cooperative, integrative behaviour at the European level, or passed over almost entirely by adherents of the 'EU-as-actor' approach.

The foreign policy analyst, on the other hand, concerned both to track and to analyse actor-directed policy at the international level, can and arguably should offer a less restrictive definition of European foreign policy. The position taken here is that to be useful for analytical purposes, the concept has to encompass the fragmented nature of agency at the European level and the variety of forms of action. Observation of foreign policy activity in Europe reflecting what Hill calls 'the sum of what the EU and its member states do in international relations' (Hill 1998: 18) should lead us to conclude that defining European foreign policy as 'member states' foreign policy' or as 'EU foreign policy' or, indeed, as 'EC foreign policy' (H. Smith 1998) is too restrictive. European governance in the foreign policy field appears to take all three forms which can be differentiated for analytical purposes, though, it should be stressed, a key research task that the foreign policy analyst can undertake is to establish the extent to which these types have become interwoven over time (Peterson 1998). Clearly, the 
more extensive the interrelationships between them, the more justified we are in using the label 'European foreign policy'.

\section{An FPA framework}

We have argued so far that existing approaches to understanding Europe's global role are limited. Institutionalist analyses of European foreign policy in particular are limited by a set of weaknesses, the most serious of which are the absence of a developed view of state/actor behaviour, a simplified view of policy-making processes and, as highlighted in the last section, a restrictive definition of foreign policy in a European context. The possibility of FPA providing an approach that fills those gaps is dependent upon the adaptability of traditional FPA. If FPA remains tied to state-centric realism, its value is clearly limited, though this should not be taken to imply that states are not important actors in European foreign policy. The argument here is that FPA is not necessarily tied to statecentricity nor is it dependent upon a realist paradigm. To summarise the rest of the argument, the essence of FPA is that it offers an actor rather than a state perspective and, equally important, it provides a policy focus at the international level. Building upon these premises, this section outlines and develops an appropriate analytical framework. A starting point is provided by posing six standard FPA questions:

1 Who makes European foreign policy?

2 What is the nature of the European foreign policy process?

3 What issues constitute the European foreign policy agenda?

4 What instruments are deployed by European foreign policy?

5 What is the context within which policy is made?

6 What are the outputs generated by the policy process?

It is assumed that the elements of this framework - actors, processes, issues, instruments, context and outputs - are interrelated and constitute a foreign policy system in action. Thus, the nature of the policy process is affected by the identity of the actors involved, the issues being dealt with, the policy instruments available and, not least, the context within which policy is made. These interrelationships in turn generate the outputs from the system (Clarke and White 1989).

Before the elements of the analytical framework can be further specified, however, we need to underline the conceptual analysis in the last section by clearly identifying the different types or 'subsystems' of European foreign policy.

'Community foreign policy' refers to the foreign policy of the European Community which emerged as a direct consequence of the establishment of the original European Communities in 1957. These powers established by the Treaties of Rome codify the external consequences of the Common Commercial Policy and cover principally trade and development relations with third parties. 
From an adapted FPA perspective, this form of policy-making is uncontentiously foreign policy and can be regarded as constituting the foreign economic policy dimension of European foreign policy.

'Union foreign policy' refers to the more overtly political dimensions of European foreign policy and consists of the coordination of the foreign policies of member states in a process that, until the Single European Act of 1986, was pursued outside the legal framework of the Community. This type of policy was established in the early 1970s as an intergovernmental process known as European political cooperation. The TEU upgraded this process and replaced EPC with a commitment under the terms of TEU to establish a Common Foreign and Security Policy. CFSP was established as a separate 'pillar' of the European Union; hence the label adopted here despite its prescriptive, federalist connotations (Smith 1996a).

'National foreign policy' refers to the separate foreign policies of member states which have continued to exist and indeed to thrive. What is important in the context of establishing the parameters of a European system of foreign policy, however, is the extent to which the foreign policies of member states have been transformed by the process of operating within the EU institutional context. Hill and Wallace offer an initial description of the transformed context in which member states operate. 'Habits of cooperation, accepted advantages of shared information, responses to common threats, cost saving through increased collaboration, have all significantly altered patterns of national policymaking' (1996: 12).

Their conclusion offers a useful but, from an FPA perspective, limited characterisation of the relationship between the three types of European foreign policy. 'This is an intensive system of external relations in which the cooperating actors which constitute the system intertwine' (1996: 12). While the problem with the term 'external relations' has already been noted, if the various elements of a European foreign policy system are interrelated we must assume that the system includes but extends beyond the 'cooperating actors'. Having identified different types of governance in this field, we can begin to explore the extent to which each type attracts a different cluster of actors, is characterised by a different policy process, operates within a distinctive context and across a specific agenda, utilises different sorts of policy instruments, and generates different outputs.

\section{Actors and policy-making}

The first and possibly the most important element in our integrated FPA framework attempts to relate actors to policy-making by a sustained focus on the nature and dynamics of the policy process or, more accurately, policy processes given the different types of European foreign policy identified here. For analytical purposes, this element naturally subdivides into studying the different stages of the policy process from policy-making/formulation through to policy implementation via policy instruments. We can assume that the nature of the policy process - and the identity of the key actors involved - depends upon 
the type of European foreign policy being analysed. If foreign policy in this context is defined in political terms as Union policy, then European foreign policy can be described and analysed as essentially an intergovernmental process. This suggests that the governments of the member states effectively control a process where unanimity is the rule.

The problem with this model of policy-making is that the notion of intergovernmentalism also implies that member states remain the 'classical sovereign states of realist theory', independent and autonomous in the defence of their respective national interests (Hill and Wallace 1996: 11). But, for many institutionalists like Wessels and Edwards, this understates the degree to which member states are locked into a 'complex network of institutions and procedures' at the European level. Constant interaction within that network serves to limit the autonomy of any member state, even the most powerful (Wessels 1991; Edwards 1996). This point is again neatly summarised by Hill and Wallace. 'Intergovernmentalism in theory does not erode sovereignty; in practice, over time, it too has ties that bind' (Hill and Wallace 1996: 11).

While the nature of the Union policy process can be debated, other types of policy appear to show even more clearly the limits of state power. If European foreign policy is defined as Community policy, the process of policy-making can be assumed to be more akin to the Community model of decision-making, with the European Commission in theory at least playing the role of principal actor at the European level. Once again, however, a simple characterisation of the policymaking process is likely to be deceptive with respect to establishing who controls what. As Michael Smith notes, some areas of foreign economic policy, like monetary policy and investment, have never been subject to a Community-level policy-making process (Smith 1996: 249). And even in areas like trade policy where in theory the Commission has exclusive competence, a careful reading of the relevant Articles of the Treaty of Rome shows that there is a division of powers between the Commission and the Council of Ministers.

\section{Capabilities and instruments}

The critical link in the foreign policy literature between policy process and output is the existence or otherwise of capabilities, resources which can be converted into usable policy instruments. Reflecting and to some extent defining its limited actor status, the EU as a whole appears to have had an incomplete set of policy instruments of varying effectiveness. While a powerful set of economic and financial instruments has been developed over time in Community policy, policy instruments deployed in Union policy are either much weaker or nonexistent. With respect to diplomacy, a growing dissatisfaction with the effectiveness of diplomatic statements led to the adoption of 'common position' and 'joint action' mechanisms in the 1993 TEU. That Treaty also finally addressed the significant absence of a military capability/set of instruments at the European level. The replacement of European political cooperation by a commitment to a Common Foreign and Security Policy and the subsequent development of the 
European Rapid Reaction Force signalled a determination at least to move forward on that front, initially through the mechanism of the Western European Union but ultimately through the creation of a European Security and Defence Policy. We need still to explore whether these aspirations have been converted into a substantial and effective European military capability.

The effectiveness of policy instruments may well reflect the issue being addressed. Two related analytical concerns have dominated the FPA literature on issues, and both are equally relevant to a discussion of issues and policy areas in a European foreign policy context. The first relates to the range of issues that constitute the foreign policy agenda and how different issues attract different sets of actors and are handled by different policy processes. The central point in that literature is that for a variety of reasons the agenda, particularly for 'modernised' states, has dramatically expanded. This raises questions about the effectiveness of what might be called systems of policy management. A related focus is the extent to which an expanded agenda of issues creates 'boundary' problems. These boundaries are of two types, broadly between economic and political issues - or, as Edward Morse (1970) described it - between 'high' and 'low' policy issues and second, issues which cross the 'boundary' between domestic and international politics. The boundary problem dimension also raises questions about policy management but, in addition, introduces problems relating to the political sensitivities of member states.

The European foreign policy agenda has clearly expanded, particularly in recent years as a result of the end of the Cold War. Since 1989, the 'new Europe' has been confronted by a host of new issues and old issues in a new form that raise broadly the same analytical questions as those familiar to foreign policy analysts. Maintaining coherence across an expanding agenda and dealing with boundary problems demands for the EU as for developed states, a constant search for new instruments and new institutional mechanisms to manage policy. One example of the former are the Europe Agreements reached with Central and Eastern European countries, while the succession of institutional reforms in the European Commission through the 1990s illustrates a continuing attempt at a European institutional level to manage more effectively both the growing politicisation of EU activities and the ever more blurred boundary between economic and political issues.

\section{Policy context}

An important set of variables used in foreign policy system models relates to the context within which policy is made, often referred to in that literature as the 'setting' or 'environment' of policy-making. These variables are generally conceived of from this perspective as constituting important 'inputs' into the foreign policy system, helping to define the parameters within which the system can operate. If context is subdivided into internal and external elements, this aspect of the analytical framework can be further elucidated. The 'internal' setting though is more complex in a multi-level European policy context than in a state. Account has to 
be taken of intra-EU factors as well as the traditional 'domestic' intra-state setting to the extent that they impact upon European foreign policy.

At the EU 'internal' level, analysts might focus on, for example, the constitutional context - broadly who is given what powers or competences to do what in foreign policy-making. Like many other contextual elements, constitutional provisions are a dynamic, changing element in the policy process. Not only have we seen a series of treaties refine and expand the constitutional provisions established in the 1957 Rome Treaties but European Court of Justice interpretations can also change the context of foreign policy-making in the broadly defined sense in which the term is being used here. Another dynamic element of the internal environment is the development of a burgeoning diplomatic machinery controlled by the Commission. This extends a permanent network of representation abroad together with a growing number of diplomatic missions accredited to the EU/Commission. This element links to the multi-level nature of the decision-making process which not only helps to shape the policy process(es) but should also be regarded as part of the context within which policy-making takes place. As summarised by William Wallace, multi-level governance denotes inter alia 'complexity and the contested character of policy-making' which in turn 'makes for dispersed and disjointed decisions, and for incomplete implementation' (Wallace 1996: 445).

From an external perspective, similarly, different factors can be identified and built into the analysis. The obvious example that has been dealt with at length in the literature, though not necessarily from this analytical perspective, is the impact of the end of the Cold War on the foreign policy process in the new Europe. As Michael Smith notes, underlining the interrelationship between the elements of our analytical framework, the transformations in Europe have dramatically 'reshaped both the context and the agenda' of what he calls 'the EC's external relations'. One important element within this transformed policy environment, though ostensibly part of the internal policy agenda, has been the establishment of the Single Market which has major ramifications for European foreign policy (Smith 1997: 280ff).

It should not be forgotten at this point that FPA can also provide a framework for analysing member states' foreign policy as well as the other subsystems of European foreign policy. The 'Europeanised' context within which national foreign policy is made and implemented is a particularly important element within that framework. While there is a need for more comparative research here on foreign policy, the indications are that this dynamic policy context poses major problems for national governments in terms of constructing an effective machinery for coordinating policy at different levels of activity (Wright 1996). On the other hand, there is some evidence with respect to smaller member states that operating through EPC/CFSP has, in Ben Tonra's conclusion, 'improved the effectiveness, broadened the range and increased the capabilities of foreign policy-making' (1997: 197 and 2001). 


\section{Applying an FPA framework to European foreign policy}

If the previous section is taken as an indicative attempt to flesh out an appropriate FPA framework, the final section of this chapter reports briefly on the attempt to test out the framework in a book-length study of European foreign policy (White 2001). Summary conclusions are drawn here with respect to the utility of the framework in analysing the development of European foreign policy. The first and arguably the most important substantive conclusion that can be drawn from the study is that, from a thirty year perspective, the progress made towards a common European foreign policy, given the strengths and divergence of interests, has been remarkable - even if there is still a long way to go. It is argued that an FPA approach focused on the relationship between policy processes and policy output over time does effectively highlight evolutionary trends at work in European foreign policy (Peterson 1998: 14-15).

Second, the three subsystems of European foreign policy identified earlier remain separate and European foreign policy can appropriately be characterised as 'subsystem dominant'. But, as the study shows, there has undoubtedly been a growing interaction between these subsystems over time. Community, Union and national foreign policies are increasingly intertwined at both policy-making and policy implementation levels. Union and national foreign policies may still be described as intergovernmental in form - apparently reinforced structurally by changes following the Amsterdam Treaty - but the development of transnational policy networks operating increasingly across both the pillar framework and our subsystems makes control of the process by governments, individually or collectively, difficult though not, of course, impossible (indeed, following the Treaty of Amsterdam, the national veto appeared explicitly in treaty form). The more established these networks have become, the more the members of them have become socialised into accepting particular sets of values and norms. This means that there is a more or less collective commitment to reach agreements and to push the process of coordination further forward.

Growing linkages across different foreign policy systems are perhaps most apparent at the operational end of the process. In this context, it will be particularly interesting to track the development of 'common strategies' which were designed explicitly to link cross-pillar decision-making to capabilities and instruments drawn from all three types of European foreign policy. A useful way of characterising the impact of piecemeal changes to the policy process over time, particularly at the 'subsystemic' or 'policy-shaping' level of decisionmaking (Peterson 1995), is to deploy the 'ratchet' metaphor. Peterson (1998: 16), for example, gives the establishment at Amsterdam of the Policy Planning and Early Warning Unit as an illustration of the 'ratchet effect' on foreign policy coordination. The more recent formal establishment of the various political and military committees in Brussels as a result of developments in European defence policy since St Malo might serve as examples from the defence/security field of 
institutional mechanisms that are likely further to 'rachet up' cooperation and foster incremental change.

Third, within European foreign policy, the individual foreign policies of member states remain very important, possibly still more important than either Community or Union foreign policies in terms of their overall impact on world politics. Clearly, member state foreign policies have not been replaced by European foreign policy. However, as illustrated in the study by a detailed chapter on Britain, the foreign policies of member states are scarcely recognisable as traditional foreign policy. The context in which they operate, the processes through which they are made and their outputs all show very clearly the growing impact of Europeanisation.

Fourth, despite the focus in much of the literature and the media on specific policy failures and the ineffectiveness of European foreign policy more generally, it is now possible to review policy output over time and begin to talk of some policy successes which might be set against a more negative appraisal. Though, consistent with our FPA approach, the study concentrates more on process than outputs, European foreign policy (EFP) and specifically CFSP have arguably had a number of successes, though criteria for establishing success and failure are not easily established (Jørgensen 1998). One obvious candidate from the case studies undertaken in the study is European policy towards South Africa since the 1970s (White 2001). Certainly, the study reinforces Peterson's view that member states have moved from 'nominally' adjusting their foreign policies in the 1970s and 1980s to a point 'where something which deserves the name "common" has been created in the 1990s' (1998: 4).

Fifth, though progress is being made, albeit haltingly, towards a common European foreign policy, there are continuing pressures from within the EU and without to present a united face to the outside world and thus to move further, beyond a common and towards a single European foreign policy. These pressures are unlikely to go away; indeed, they are likely to be reinforced by precisely the issues that currently preoccupy the EU. In particular, economic and monetary union has major implications for the future of EFP. The physical circulation of the euro as the single currency from 2002, as Bonvicini argues, means that the EU 'will inevitably be forced to play a bigger international role. As a "global currency", the euro will require a [single] policy towards the dollar and the yen, with unavoidable repercussions for the Union's foreign policy' (1998: 73).

Finally, the study concludes that the use of the term 'European foreign policy' rather than any of the more commonly used alternative concepts has been justified as a focus of description and analysis. European foreign policy is not simply a convenient shorthand for the collective foreign policies of member states. Nor is it simply 'EU foreign policy', which appears to be the preferred label of most commentators. The study establishes that there are different types of foreign policy systems in the European Union and that these different types increasingly overlap. We therefore need a term which encompasses them but 
goes beyond a narrow focus on any one of them. There are, of course, different ways of conceptualising European foreign policy.

One possible criticism of the particular way EFP is conceptualised here is to say that it is too EU-centred or possibly too 'Eurocentric'. Hill develops the argument that European foreign policy gets 'made' in a variety of ways that increasingly involve what he calls a 'mixity of organisations and actors' that extend beyond the EU family of players. These other actors - non-EU states, nonEuropean states like the US, other non-EU organisations (governmental and non-governmental) all overlap the EU's areas of activity. His general point is that contemporary world politics as a whole is characterised by 'overlapping institutionalism' and that separating out the activities of different regional players for analysis is increasingly problematic (Hill 1998: 43-6). This is an important argument and there are examples throughout the study of the role played by non-EU actors in ostensibly European foreign policy activities. But, as Hill himself comments, he is talking about 'foreign policy in Europe;' rather than 'European foreign policy' and, to the extent that these terms have different connotations, his argument does not undermine the way that European foreign policy has been conceptualised here with an FPA focus on the different actors and policy processes within the EU.

If, as has been suggested, the study of CFSP remains at a 'pretheoretical stage', the same comment is even more justified with respect to the study of European foreign policy (Ginsberg 1999: 429). At this stage, a variety of theoretical approaches is to be welcomed. A strong case has been made here that a foreign policy analysis approach suitably adapted has a useful contribution to make to an understanding of European foreign policy and, more widely, to an understanding of Europe's global role.

\section{Notes}

This chapter is adapted from B. White (1999), 'The European Challenge to Foreign Policy Analysis', European Journal of International Relations, 5:1, 37-66. 